\title{
Pesquisa, extensão e invisibilidades sociais: reflexões sobre ausências e emergências a partir da Geografia brasileira
}

Cristiano Quaresma de Paula

Universidade Federal do Pará, Brasil

cqpgeo@gmail.com

(iD) orcid.org/0000-0002-0220-909X

RECEPCIÓN: 24/06/19

ACEPTACIÓN FINAL: 30/08/19

\section{Resumo}

Em diálogo com Boaventura de Sousa Santos, avalia-se que, na ciência moderna, as presenças de sujeitos, e por conseguinte dos seus territórios, são mais restritas do que as ausências. Ao concluir a tese "Geografia(s) da pesca artesanal brasileira", verificou-se que as invisibilidades sociais, no caso dos pescadores, frequentemente são produzidas ou reafirmadas nas ciências. Estas geografias das ausências, ganham operacionalidade pela adoção dos paradigmas que viabilizam a modernização do território. A produção de dissertações e teses tem promovido o enfrentamento das ausências na pesquisa, contudo o papel da extensão universitária ainda tem sido restrito. As ausências são produzidas por meio de paradigmas que defendem o conhecimento científico como saber único, o tempo como uma reta linear, hierarquias entre grupos e territórios, o global como escala dominante, e o produtivismo como critério inquestionável. No entanto, a promoção de geografias das emergências ocorre quando se evidencia contextos sociais de recuperação da autonomia nos territórios tradicionais, defendemse os diversos saberes, as multitemporalidades, as diferenças, a escala local (do território) e formas tradicionais de produção. Diante disso, o artigo apresenta reflexões sobre o papel da ciência, destacando da extensão universitária, no enfrentamento às invisibilidades sociais, destacando os estudos sobre pesca artesanal na Geografia brasileira, mas que não se limita a estes, no movimento de superação das ausências e promoção de emergências.

Palavras-chave: geografia, Brasil, ausências, emergências, pescadores.
Research, Extension and Social Invisibilities: reflections on absences and emergencies from Brazilian Geography

\section{Abstract}

In dialogue with Boaventura de Sousa Santos, it is evaluated that, in modern science, the presence of subjects, and therefore of their territories, is more restricted than absences. Concluding the thesis "Geography (s) of Brazilian artisanal fishing", it was discovered that social invisibilities, in the case of fishermen, often occur or reaffirm in science. These geographies of absences gain operability by adopting the paradigms that allow the modernization of the territory. The production of dissertations and thesis has promoted the confrontation of absences in research, however, the role of university extension has still been restricted. Absences occur through paradigms that defend scientific knowledge as unique knowledge, time as a linear line, hierarchies between groups and territories, global as a dominant scale and productivism as an unquestionable criterion. However, the promotion of emergency geographies occurs when social contexts of recovery of autonomy in traditional territories are evidenced, defending the diverse knowledge, multitemporalia, differences, local scale (territory) and traditional forms of production. Given this, the article presents reflections on the role of science, highlighting the university extension, facing social invisibilities, highlighting studies on artisanal fisheries in Brazilian geography, but not limited to them, in the movement to overcome absences and promote emergencies.

Keywords: geography, Brazil, absences emergencies, fishermen.
Investigación, extensión e invisibilizaciones sociales: reflexiones sobre las ausencias y emergencias a partir de la Geografía brasileira

\section{Resumen}

En diálogo con Boaventura de Sousa Santos, se evalúa que, en la ciencia moderna, la presencia de sujetos, y por lo tanto de sus territorios, es más restringida que las ausencias. Al concluir la tesis "Geografía (s) de la pesca artesanal brasileña", se descubrió que las invisibilidades sociales, en el caso de los pescadores, a menudo se producen o reafirman en las ciencias. Estas geografías de ausencias ganan operatividad mediante la adopción de los paradigmas que permiten la modernización del territorio. La producción de disertaciones y tesis ha promovido la confrontación de ausencias en la investigación; sin embargo, el papel de la extensión universitaria aun es restringido. Las ausencias se producen a través de paradigmas que defienden el conocimiento científico como conocimiento único, el tiempo como lineal, jerarquías entre grupos y territorios, lo global como escala dominante y el productivismo como criterio incuestionable. Sin embargo, la promoción de geografías de emergencias se produce cuando se evidencian contextos sociales de recuperación de la autonomía en territorios tradicionales, defendiendo los diversos conocimientos, multitemporalidades, diferencias, escala local (territorio) y formas tradicionales de producción. Ante esto, el artículo presenta reflexiones sobre el papel de la ciencia, destaca la extensión universitaria frente a las invisibilidades sociales, resalta los estudios sobre la pesca artesanal en la geografía brasilera, pero sin limitarse a ellos, en el movimiento de superar las ausencias y promover emergencias.

Palabras clave: geografía, Brasil, ausências, emergências, pescadores.

Para citación de este artículo: Quaresma de Paula, C. (2019). Pesquisa, extensão e invisibilidades sociais: reflexões sobre ausências e emergências a partir da Geografia brasileira. +E: Revista de Extensión Universitaria, 9(11), 10-31. doi: 10.14409/extension.v9i11.Jul-Dic.8676. 


\section{Introdução}

Este artigo problematiza sobre a ciência no tempo presente e a sua relação com a produção e enfrentamento de invisibilidades sociais. Tais reflexões foram propostas na Tese Geografia(s) da Pesca Artesanal Brasileira (De Paula, 2018), onde, em diálogo com Boaventura de Sousa Santos (2007), foi destacado o papel da Geografia na constituição de ausências, e na promoção de emergências de sujeitos e territórios.

Destaca-se que, no Brasil, as universidades são constituídas sobre três pilares: ensino, pesquisa e extensão. Estes são indissociáveis, mas a extensão universitária, que proporciona a maior visibilidade de sujeitos e territórios, não costuma ser destacada. Por isso, com base na referida pesquisa de De Paula (2018) serão destacados os projetos de extensão, realizados por geógrafos, que envolvem pescadores artesanais.

Na Geografia as ausências e emergências tem expressão no território, concebido como espaço multiescalar e multidimensional, onde se destacam as relações de poder (Raffestin, 1980), que podem ser tanto de domínio, quanto de prestígio. Elaborando esta interpretação, no âmbito da análise territorial, as ausências decorrem da imposição de paradigmas da modernização, com o apoio de sintagmas que os afirmam, de forma que o uso tradicional do território é apresentado como arcaico ou atrasado, e, por isso, suscetível a substituição por empreendimentos modernos. Memória e esquecimento são fundamentais na dinâmica territorial (Raffestin, 2012).

Para enfrentar ausências e promover as emergências, no âmbito da acadêmica, se faz necessário desenvolver projetos de pesquisa, ensino e extensão que coloquem em evidência tais sujeitos, que até então a ciência subalternizou. Sobretudo, destaca-se o papel da extensão universitária pela sua capacidade de transitar para além dos muros da universidade, evidenciando o território dos sujeitos, e agregando em seus objetivos demandas concretas das comunidades.

Os diálogos com os sujeitos expõem as faces da modernização nos territórios tradicionais (De Paula \& Suertegaray, 2018), bem como as estratégias das comunidades tradicionais para a recuperação da autonomia nos/dos territórios. No entanto, tem-se que reconhecer que as ausências, intencionalmente ou não, continuam sendo amplamente produzidas, o que merece atenção e crítica, questionando a predileção pelos paradigmas da modernização na ciência, nesse caso na Geografia.

Ressalta-se que as análises, as quais deram sustento a essas reflexões, dizem respeito aos povos dos mares, lagos e rios, os pescadores artesanais brasileiros. No entanto, tais compreensões podem permitir discussões sobre outros povos e comunidades tradicionais, como remanescentes de quilombolas, indígenas, povos de ciganos, povos de terreiro, entre muitos outros, que se evidenciam no Brasil e em outros países da América Latina e do mundo.

Cabe destacar que a presente discussão está embasada metodologicamente na teoria do pensamento complexo proposta por Morin (1990) e outros. Desta forma, as propostas analisadas se orientam pelos princípios da dialógica, recursão organizacional, e hologramático. Entre as técnicas de pesquisa empregadas destaca-se a análise do conteúdo de dissertações, teses e denúncias dos movimentos sociais; questionário respondido por 
Geógrafos que discutem a pesca artesanal em seus projetos; e trabalhos de campo e produções cartográficas ${ }^{1}$.

A estrutura do artigo parte da expressão da pesca artesanal, em projetos de extensão promovidos por geógrafos brasileiros. Na sequência situa a discussão a respeito de ausências e emergências na problemática territorial. Com base nisso, discute-se e apresenta-se os paradigmas da modernização que provocam ausências de sujeitos e territórios, assim como a reação das comunidades tradicionais, na forma de luta, para a recuperação da autonomia no/do território como promoção de emergências.

Diante do exposto, o principal objetivo desse artigo é destacar o papel da ciência, destacando da extensão universitária, contextualizada na Geografia, na promoção e reafirmação de invisibilidades sociais, como ocorre com as comunidades tradicionais de pescadores.

\section{Os pescadores artesanais em projetos de extensão}

Compreendendo que é recente a emergência da pesca artesanal na pesquisa geográfica, quando se analisa tal expressão na extensão, verifica-se que é ainda mais incipiente (Figuras 1 e 2). No entanto, cabe destacar tais iniciativas, que tèm contribuído na promoção de emergências na Geografia brasileira.

Tal participação está muito concentrada nos estados do Rio de Janeiro e Bahia. Entre os projetos de extensão que os pesquisadores apontaram que participam, cabe destacar no Rio de Janeiro o projeto "Pescando por Meio de Redes Sociais" NUTEMC - Núcleo de Pesquisa e Extensão: Urbano, Território e Mudanças Contemporâneas - UERJ/FFP. A partir da demanda das comunidades de pescadores, o referido grupo, em parceria com o Ministério da Previdência Social promoveram "oficinas" para que os pescadores tomassem conhecimento dos seus direitos previdenciários e trabalhistas.

Na Bahia, um exemplo é o projeto "Campanha Nacional pela Regularização dos Territórios das Comunidades Tradicionais Pesqueiras no estado da Bahia: Desafios e Perspectivas" desenvolvido pelo GeograFar - A Geografia dos Assentamentos na Área Rural - UFBA. Este, está comprometido com a campanha promovida pelo Moviments dos Pescadores e Pescadoras Artesanais - MPP - para a garantia e salvaguarda, em lei, dos territórios das comunidades tradicionais de pescadores artesanais. Também na região Nordeste no estado do Rio Grande do Norte, foi apontado o projeto "Pescador Artesanal de Cajueiro (Touros - RN) na Perspectiva da Inclusão Social e da Cidadania" promovido pelo Grupo de Estudos Urbanos e Regionais - UFRN.

No estado do Pará há participação de um pesquisador no projeto "Conservação e Uso dos Recursos Naturais em Áreas Protegidas no Nordeste Paraense" promovido pelo GEPPAM - Grupo de Estudos Paisagem e Planejamento Ambiental - UFPA. Também se destaca

1) Foram analisadas 71 dissertações e teses sobre a pesca artesanal, defendidas na Geografia brasileira entre 1982 e 2015, assim como denúncias dos movimentos sociais de pescadores, destacadamente do Blog "Pelo território pesqueiro" do Movimento dos Pescadores e Pescadoras Artesanais - MPP e do Relatório "Conflitos Socioambientais e Violações de Direitos Humanos em Comunidades Tradicionais Pesqueiras no Brasil" promovido pelo Conselho Pastoral dos Pescadores - CPP (Tomáz \& Santos, 2016). Os questionários foram respondido online (plataforma google sheets) por 74 geógrafos(s). Os trabalhos de campo foram realizados junto a Grupos de Pesquisa que abordam a pesca artesanal, e em reuniões dos movimentos sociais. 
o Projeto "Mapeamento Participativo nas Comunidades Ribeirinhas da FLONA de Tefé AM" promovido pelo NEGA - Núcleo de Estudos Geografia e Ambiente - UFRGS. Nesses, a atuação se dá junto aos conselhos deliberativos de unidades de conservação, discutindo propostas de manejo dos recursos ambientais com os comunitários de forma participativa.

Dos pesquisadores que responderam os questionários e participam de projetos de extensão, $43,35 \%$ apontaram que os projetos são financiados. Outros $37,50 \%$ informam que alguns projetos são financiados e outros não. Já $18,75 \%$ afirmam que os projetos de que participam não são financiados (Figura 3).

Cinco pesquisadores que responderam os questionários apontaram o CNPq - Conselho Nacional de Desenvolvimento Científico e Tecnológico - como financiador de projetos de extensão. Sete pesquisadores apontaram as agências estaduais como órgãos de fomento à extensão. Para o financiamento dos projetos de extensão, cinco pesquisadores apontaram o Edital PROEXT - Programa de Extensão Universitária - do Ministério da Educação. Os demais financiadores apresentados são a CAPES - Coordenação de Aperfeiçoamento de Pessoal de Nível Superior - e as próprias universidades.

Figura 1. Mapa de Projetos de Extensão por Instituição.

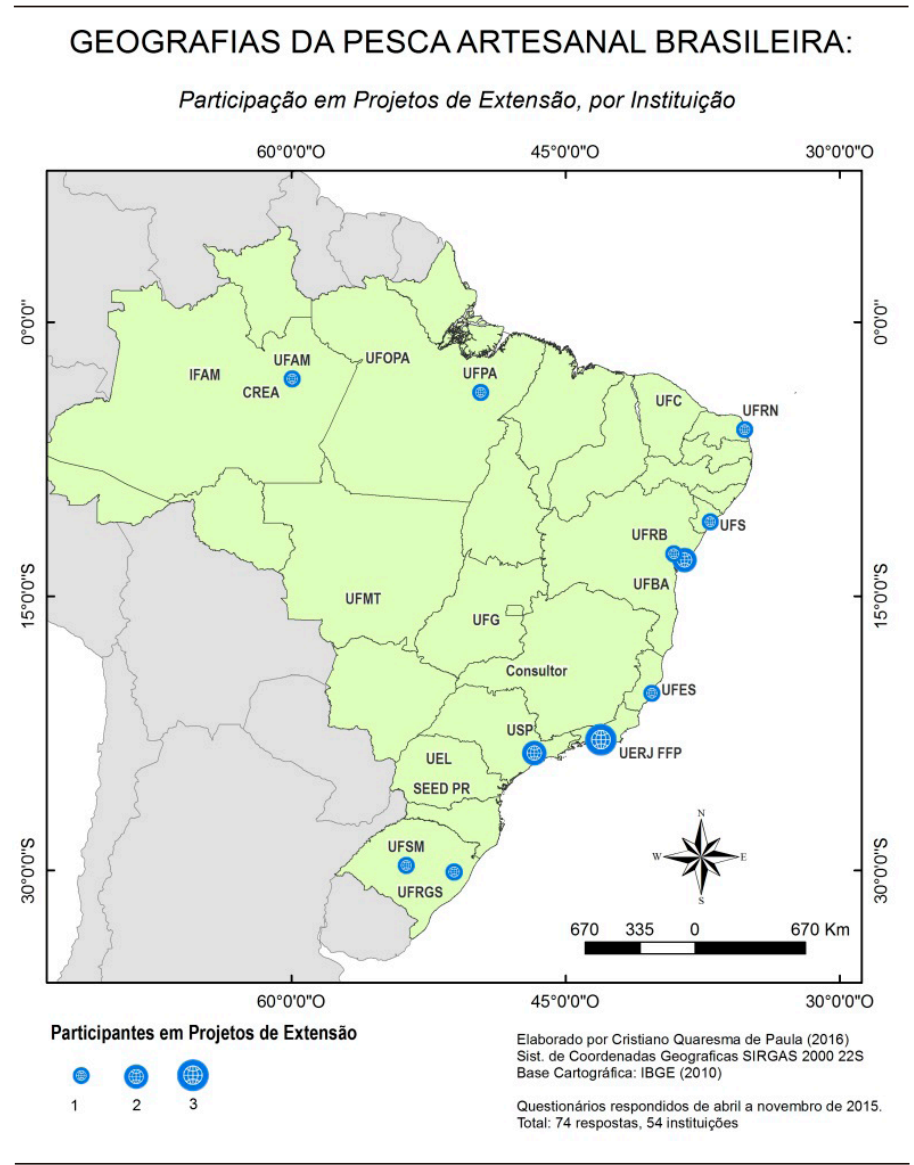

Fonte: elaborado por De Paula (2018). 
Figura 2: Mapa de Projetos de Extensão por Unidade da Federação.

GEOGRAFIAS DA PESCA ARTESANAL BRASILEIRA:

Participação em Projetos de Extensão, por UF

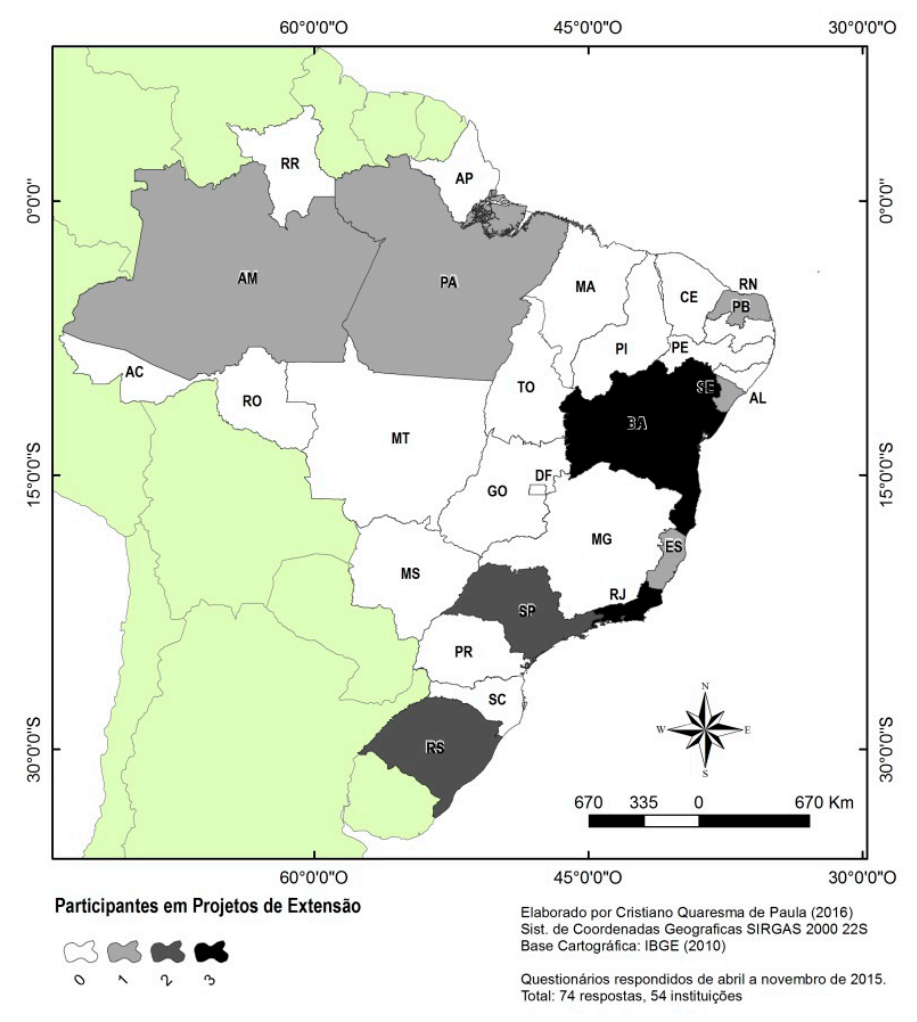

Fonte: elaborado por De Paula (2018).

Figura 3: Financiamento dos Projetos de Extensão por Região.

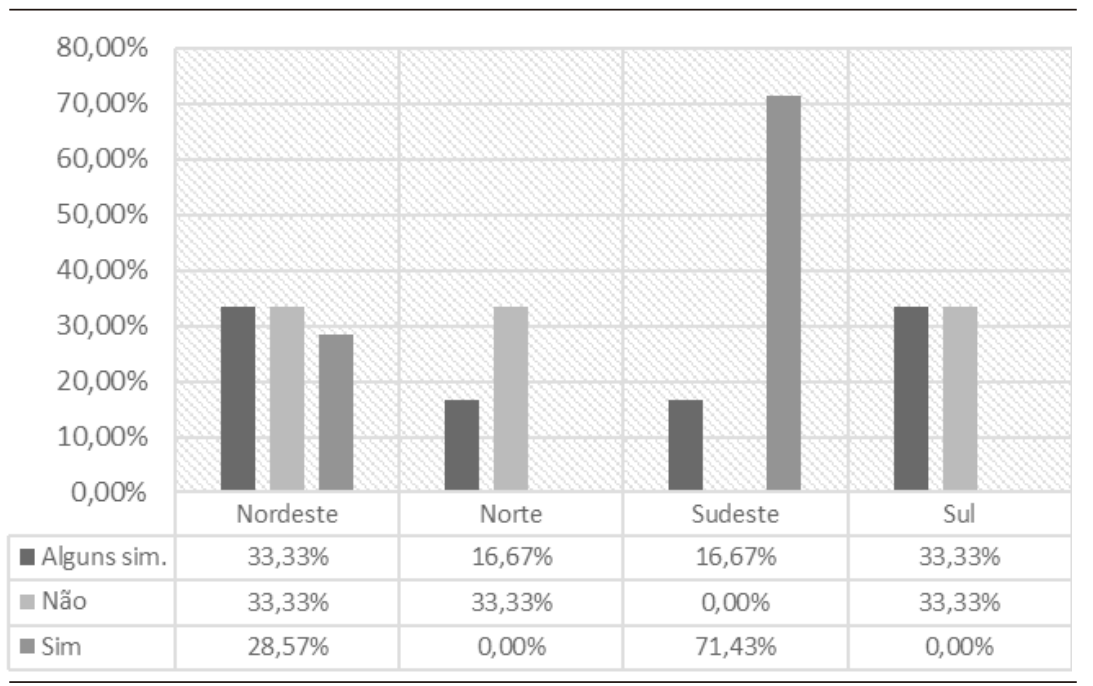

Fonte: elaborado por De Paula (2018). 
Ressalta-se que apesar de muitos projetos serem desenvolvidos sem financiamentos, a valorização da extensão depende muito do fomento, por meio de programas como o PROEXT. Editais promovidos nos governos de Luís Inácio Lula da Silva e Dilma Rousseff foram fundamentais para levar a extensão universitária até os territórios das comunidades tradicionais de pescadores artesanais. Contudo essa perspectiva política foi interrompida em 2016, com medidas como a Proposta de Emenda à Constituição - PEC 55 de 2016, que congela os gastos públicos por 20 anos, do Governo Michel Temer, e tem continuidade no Governo Bolsonaro, com o contingenciamento de recursos das universidades e institutos federais, redução de bolsas de estudos, e ofensivas às ciências humanas e sociais.

\section{Modernização e territórios tradicionais na análise geográfica}

Como apresenta Arzeno (2018:4) o conceito de território no campo da extensão universitária, aparece como um "terreno de jogo", no qual teoria se volta à prática, se estabelecem trocas, onde a universidade se conecta de maneira concreta à realidade social para intervir, e nesse processo gera novas aprendizagens. Em diálogo com movimentos sociais, De Paula (2018) enaltece o avanço da modernização sobre os territórios das comunidades tradicionais, comprometendo a perenidade da própria comunidade. Vislumbrar a relação entre território tradicional e território da modernização, é fundamental para identificar o papel da ciência na produção de invisibilidades sociais, e estabelecer estratégias para a pesquisa, ensino, e sobretudo, para a extensão.

Sousa Santos et al. (2006) entende que as ausências são amplamente produzidas, com destaque no meio científico. As "invisibilidades" sociais decorrem também da ausência dos sujeitos nas ações de pesquisa, ensino e extensão, inclusive da Geografia. Sabe-se que é impossível tratar de todas as dimensões de determinada realidade, no entanto, questiona-se a predileção por determinada classe ou grupo. As ausências são produzidas amplamente na Geografia e decorrem da promoção do discurso prioritariamente a partir do dominante, privilegiando alguma cultura, e promovendo determinada racionalidade.

Destarte ausências e emergências na Geografia provocam a pensar as mesmas na dimensão espacial. Diversos geógrafos assumem esse propósito tratando das "invisibilidades", cujas abordagens têm em comum a compreensão de que determinados sujeitos, em contextos sociais diversos, são invisibilizados no espaço. Nesse sentido, concorda-se com Arzeno:

"Estas formas de pensar el espacio (geográfico) lo sitúan en un lugar central en la estructuración de las relaciones y procesos sociales, en la producción de la historia, y permiten superar aquellas visiones que han sido dominantes por mucho tiempo dentro del ámbito académico y que aún predominan desde el "sentido común", que entienden al espacio como "conteneder" de objetos, como receptáculo, como escenario donde transcurre la vida social". (2018:6)

Para essa discussão sobre povos tradicionais é significativo retomar a relação entre território e modernidade na produção de ausências. A separação entre sociedade e natureza na Geografia, se deu em contexto de ciência moderna ocidental (Suertegaray, 2017). Nessa perspectiva também se separou as inúmeras possibilidades de compreensão da sociedade e da natureza. Como produto desse processo a Geografia moderna expõe em suas análi- 
ses fragmentos da sociedade/natureza no espaço (Suertegaray e De Paula, 2019). Quanto aos sujeitos, os geógrafos são levados a expor aqueles que estão mais visíveis no contexto social. Logo, fica à margem da pesquisa, ensino e extensão aqueles que se encontram em marginalidade social e que não se explicam por elementos isolados na análise.

Silva (2017) toma o exemplo dos "vazios demográficos", como promoção de invisibilidades pelos geógrafos brasileiros dos anos 1970 e 1980. Entende-se que os vazios demográficos correspondem àcompreensão do espaço a partir da lógica dominante, no caso a da industrialização e da urbanização, expondo um discurso comprometido com o desenvolvimento econômico (Sousa Santos, 2002), por meio da modernização. Essa compreensão exclui das análises todos os sujeitos que não estão inseridos nesse processo de desenvolvimento e não correspondem ao projeto de modernização proposto. Seus territórios são apresentados como territórios a ocupar. Soma-se a isso o fato de que esses sujeitos não se explicam por meio da razão da ciência geográfica moderna, por não separarem a sociedade da natureza e por estabelecerem outras lógicas de relações sociais. Consequentemente quando identificados (não analisados) são apresentados como arcaicos, estagnados, miseráveis, e obstáculos para o progresso da sociedade, uma vez que o ponto de vista se estabelece a partir do moderno/global.

Deve-se questionar o discurso da modernização que resulta em invisibilidades dos sujeitos sociais e ausências nas análises e ações geográficas. Uma vez que esse discurso é elaborado fora do lugar, torna-se fundamental retomar a noção de "colonialidade do poder", a qual se efetiva por meio de dispositivos, no âmbito dos Estados, de criação de identidades homogêneas através de políticas de subjetivação, bem como na manutenção da governabilidade a partir das potencias hegemônicas do sistema-mundo moderno/colonial (Gómez, 2005). Isso se realiza em contextos que Sousa Santos (2007) chama de "regresso colonizador", ou seja, na ressurgência de formas de governo colonial tanto nas cidades metropolitanas, quanto naquelas anteriormente sujeitas ao colonialismo europeu.

No âmbito científico, promove-se ausências quando a linhas de pesquisa e editais de financiamento priorizam determinados estudos que estão comprometidos com projetos de modernização do território, evidenciando que são inseparáveis os movimentos das ciências e da sociedade, a ponto de Quijano (2005) considerar a colonialidade do poder e do saber. Nesse sentido, Sousa Santos et al. (2006) destaca a necessidade de construir outras versões da história e da ciência, para evidenciar histórias globais e multiculturais do conhecimento e superar a colonialidade do saber. Logo, entende-se a necessidade de evidenciar outas Geografias do vivido, para renovar a ciência geográfica, abrindo-a para outros sujeitos e problemáticas que não correspondem e contestam a racionalidade dominante - moderna/ ocidental para superar, no âmbito da Geografia, os efeitos da razão metonímica e proléptica de que fala Sousa Santos (2002).

A Geografia deve se abrir para as inúmeras racionalidades de uso e apropriação do espaço, ou seja, reconhecer saberes e práticas, bem como vínculos singulares que determinados grupos estabelecem com o espaço geográfico. A inserção de outras racionalidades promove na Geografia o novo, na busca por soluções para problemáticas que não foram resolvidas pelo pensamento científico, antes criadas por ele, e que promovem reflexões epistemológicas na própria Geografia. Por outro lado, a Geografia deve pensar o futuro para além do que se evidencia, reconhecendo possibilidades de conversão e rompimento 
com a linearidade do presente em busca de um futuro que se constrói no diálogo com outras perspectivas de mundo (Sousa Santos, 2007).

O caminho proposto por Sousa Santos (2007) seria de promover um espaço-tempo para o conhecimento e valorização da experiência social, no presente. Desta forma, faz-se necessário expandir o presente e contrair o futuro. Na leitura geográfica que De Paula (2018) apresenta o movimento analítico seria de enaltecer a experiência local, para reduzir a influência do global nas análises. Esta estratégia constitui um contraponto entre presente/local e futuro/global, na compreensão das geografias das ausências e geografias das emergências.

O encontro entre presente e futuro, local e global, ocorre no território, logo é fundamental reconhecer as diversas temporalidades específicas que dão significado às relações de poder. Tal análise se caracteriza como multidimensional, integrando atores, energia e informação, códigos, objetivos, estratégias, contexto espaço-temporal e o canal de relacionamento ou comunicação. Também se compreende a territorialidade humana a partir de um ciclo duplo - territorial (territorialização-desterritorialização-reterritorialização - TDR) e informacional (inovação-difusão-obsolescência - IDO), dinâmico, e constituído de continuidade e descontinuidade, em grande e pequena escala (Raffestin \& Barampama, 1998).

Na promoção de ausências o território construído na dinâmica do local é desqualificado, e o presente desvalorizado em detrimento de um futuro apresentado promissor. Para enfrentar a geografia das ausências torna-se necessário expandir o presente e enaltecer o local.

De Paula (2018) aponta que na pesca artesanal as geografias das ausências se constituem quando os geógrafos não reconhecem ou desqualificam as comunidades tradicionais, em processos de instalação de empreendimentos sobre os seus territórios. Enquanto o uso do território comunitário é considerado como superado, propõe-se novos usos que são entendidos como inovadores, a partir de um padrão global (turismo, hidrelétricas, outros). O Estado, interessado no desenvolvimento econômico, apoia tal avanço e os meios de comunicação reforçam tal discurso apresentando as comunidades como entraves para o estabelecimento de projetos, que seriam benéficos para a sociedade geral. Combater a geografia das ausências é descortinar essa falácia, abrindo espaço nas pesquisas para as comunidades tradicionais, no tempo presente, na produção de cultura, nos serviços ambientais, produção de alimentos, etc. Também é importante denunciar os processos violentos de desterritorialização a que são submetidas as comunidades.

Na promoção de geografia das emergências o empenho está em contrair o futuro e reduzir a influência do global. Destaca-se as faces da modernização no território (De Paula e Suertegaray, 2018), que se evidenciam no ambiente e na sociedade, assim como as estratégias adotadas no local para enfrentar os processos de TDR promovidos por atores externos, inseridos lógicas globais (IDO). As emergências destacam resistências no território à imposição de ideias de futuro e projetos de desenvolvimento que são alheios ao local.

As geografias das emergências, na pesca artesanal brasileira, se evidenciam na abertura da ciência geográfica às comunidades, no reconhecimento dos saberes e fazeres tradicionais como alternativas para a superação da crise ambiental e proposição de formas alternativas de desenvolvimento e gestão do território. Destaca-se as resistências das comunidades pesqueiras e seus movimentos sociais e constituição de um território de luta frente ao avanço dos empreendimentos da modernização. Desta forma, o trabalho do geógrafo, oferece instrumentos de luta evidenciando as faces da modernização no território tradicional. 
Superar as geografias das ausências e promover as geografias das emergências depende de ações de ensino, pesquisa, extensão e atuação profissional, nos quais os geógrafos passam a questionar os limites do projeto de futuro apresentado pela modernização, e apresentam como contraponto as experiências e resistências no território, em enfrentamento às relações assimétricas de poder, que resultam no fascismo territorial (Sousa Santos, 2007). $\mathrm{Na}$ extensão faz-se necessário chamar atenção para a importância da dimensão espacial geral e suas manifestações territoriais na estruturação de processos sociais, com os quais se interage nos projetos (Arzeno, 2018:10).

\section{Das ausências às emergências na pesquisa geográfica}

Boaventura de Sousa Santos (2002) destaca que enquanto a sociologia das ausências evidencia o que é ativamente produzido como não existente, na sociologia das emergências a ausência exprime possibilidades futuras, ainda por identificar e uma capacidade ainda não plenamente formada para ser executada.

Para o entendimento das geografias das ausências e das geografias das emergências, a estratégia de superação da primeira consiste em "expandir o presente", enaltecendo o local. O local é compreendido no âmbito do território tradicional, que se encontra ameaçado diante do avanço dos paradigmas da modernização. Já a promoção das geografias das emergências integra iniciativas para "contrair o futuro" que desqualifica o tradicional, assim como reduzir a influência do global. Destaca-se o processo de luta para a recuperação da autonomia das comunidades no território tradicional.

Território ganha, então, centralidade nesta interpretação geográfica das ausências e emergências. A compreensão das ausências toma por base Raffestin (2012), o qual destaca o papel da memória e do esquecimento na dinâmica territorial a partir dos eixos de compreensão paradigmático e sintagmático. Isso permite compreender a produção de território sobre territórios, por meio da criação e recriação de valores econômicos, culturais, sociais e políticos. Desta forma um novo território decorre do estabelecimento de um novo paradigma, o qual é acompanhado pela instalação de sintagmas que o evidencia. Nesse movimento territórios são construídos, desconstruídos e reconstruídos, funcionalizados, desfuncionalizados e refuncionalizados.

Por outro lado, Raffestin (1986) já apontava que a autonomia é fundamental para a manutenção de territórios e territorialidades. Para os extrativistas há uma estreita relação entre autonomia e território. Logo, a ecogênese territorial integra as noções de limite, centralidade no local da coleta e circulação. Este território se mantém por meio da comunicação, que representa o cerne dos processos de TDR. O território quando delimitado garante a manutenção da "reserva," necessária para autonomia, fator primordial para a existência do grupo.

Sousa Santos (2011), apresenta cinco monoculturas que produzem ausências no âmbito da Sociologia. Também aponta como contraponto cinco ecologias para a promoção de emergências. No âmbito das geografias das ausências serão destacados cinco paradigmas que permitem o avanço do território da modernização, por meio do estabelecimento de ausências no território tradicional com a elaboração do ignorante, atrasado, inferior, local ou particular e o improdutivo ou estéril. Na leitura geográfica contraponto é estabelecido a partir de cinco estratégias para a recuperação da autonomia no/do território 
tradicional, no âmbito dos saberes, das multitemporalidades, dos reconhecimentos das diferenças, da escala do local e da produção tradicional.

Ressalta-se que o reconhecimento dos paradigmas da modernização e da importância da autonomia das comunidades tradicionais podem orientar projetos de pesquisa, ensino, e sobretudo de extensão, comprometidos e superar ausências e promover emergências de sujeitos e territórios subalternizados.

\section{Do paradigma do saber único à autonomia nos diversos saberes}

O paradigma do saber único, no território tradicional, pode ser interpretado pelo que Quijano (2005) chama de colonialidade do saber, ou seja, o poder se estabelece a partir do desconhecimento ou da negação dos saberes de outras culturas. Como aponta Sousa Santos (2002) a visão de que a ciência moderna ocidental se constitui em uma racionalidade superior é responsável por manter as estruturas de dominação e subalternização de grupos sociais que detém outras racionalidades e conhecimentos. Esse mecanismo tem sido efetivo na constituição de ausências de sujeitos e territórios.

Para a promoção de emergências, faz-se necessário superar o paradigma do saber único, um dos alicerces da constituição dos territórios da modernização, e recuperar autonomia do território tradicional por meio da valorização dos diversos saberes.

A compreensão do conhecimento científico como verdade absoluta constitui um paradigma que o elege como base para a gestão ambiental e territorial. Essa estrutura de poder no saber sustenta a submissão dos sujeitos e dos territórios aos preceitos científicos modernos. Logo, dão suporte às atividades promotoras da modernização, as quais propõem a construção de outros territórios associados a novos usos, por meio da criação de valores culturais, sociais e políticos, que presumem que o uso tradicional está ultrapassado. Desse processo se evidenciam marcas no território (Suertegaray, 2017), ao ponto de configurar em uma problemática ambiental.

A crise ambiental e territorial foi amplamente gerada no âmbito do conhecimento científico, por meio da criação de tecnologias de extração de recursos, oferecendo suportes para industrialização, bem como em elaborações teóricas e metodológicas nas ciências humanas e sociais que compreendem a natureza enquanto recurso, cujo valor atribuído é monetário. Contraditoriamente, na atualidade, a própria ciência se considera capaz de apresentar soluções para a superação da crise que criou, como trata Morin (1996) do desconhecimento do conhecimento. Frequentemente tais soluções se apresentam em normas restritivas de uso do território, as quais excluem sujeitos que não estão inseridos nesta racionalidade. Por esses sujeitos não apartarem saberes e fazeres (Morin, 2005) fazem uso do território sob uma racionalidade que Leff (2004) chama de ambiental, a qual não promoveu tal crise.

Desta forma deve-se reconhecer e dar crédito aos saberes tradicionais na gestão ambiental e territorial, e promover diálogos de saberes. Nestes se estabelecem disputas epistemológicas (Sousa Santos, 2002, 2007), e os diversos saberes contribuem com a construção de sentidos e com a superação da ignorância. Nesta dialógica há pluralidade de conhecimentos heterogêneos, cuja interação não deve comprometer a autonomia de cada um, de forma que o conhecimento é interconhecimento (Sousa Santos, 2007).

Logo não se trata de reproduzir a unicidade do conhecimento no saber tradicional, mas de superar a situação de subalternidade deste. Neste sentido, o diálogo deve ser conscien- 
te de o que está sendo aprendido, e o que é desaprendido, pois no interconhecimento se aprende com os outros sem esquecer os próprios saberes. Nesse diálogo também deve ser enfatizado que o conhecimento científico se apresenta repleto de incertezas, que quando não reconhecidas em perspectivas complexas, promovem usos e aplicações de tecnologias, concebidas no global, que apresentam consequências irreversíveis (Sousa Santos et al., 2006) principalmente sobre o local. Logo, os conhecimentos científicos devem ser apropriados numa perspectiva contra-hegemônica.

Ao enfatizar os saberes das comunidades locais na gestão do território tradicional a Geografia contribui na promoção de "contraepistemologias" (Sousa Santos, 2007). Logo expõe diversas alternativas plurais, para o enfrentamento do capitalismo global, que através da modernização avança sobre os territórios tradicionais.

Para ilustrar esse processo serão destacados os fóruns de pescadores artesanais que ocorrem no Rio Grande do Sul - Brasil. Frente ao colapso em diversas pescarias tradicionais, e da falta de abertura do Estado às demandas dos pescadores e suas instituições (Colônias, associações, cooperativas), foram estabelecidos pelos comunitários fóruns de pescadores, que articulam esses sujeitos, suas entidades representativas, bem como técnicos de órgãos de Estado que atuam junto ao setor pesqueiro e ambiental, e organizações civis não-governamentais. Nesses espaços ocorre a gestão compartilhada territorial (De Paula, 2013) e diálogos entre saberes tradicionais e técnicos-científicos, onde a dialógica tem viabilizado a construção de consensos e importantes conquistas para os pescadores artesanais (De Paula, 2015). Através dos fóruns, os saberes tradicionais dos pescadores vêm sendo reconhecidos pelo Estado, na construção de normativas próprias como ocorreu com o Fórum da Laguna dos Patos. Também para reivindicar a reversão de processos que atingem os modos de viver das comunidades, e não garantiram a participação das mesmas na sua construção, como pode ser citado o acordo de gestão estabelecido entre o Fórum Delta do Jacuí e o órgão ambiental estadual, que reverte a proposição inicial do Plano de Manejo, e garante a pesca artesanal nos limites do Parque Estadual Delta do Jacuí.

\section{Do paradigma do tempo sincrônico à autonomia nas multitemporalidades}

Para Milton Santos (2006) no espaço coexistem diversos tempos (tempo diacrônico). No entanto, o paradigma da unicidade do tempo e da história é largamente produzido nas ciências, gerando ausências de sujeitos e territórios. A concepção sincrônica (linear) de temporalidade sustenta a ideia de "progresso, evolução, modernização, desenvolvimento, crescimento, globalização" (Sousa Santos, 2011), logo não dialoga e nega as temporalidades que se expressam no território, no presente. Do mesmo modo, ao mesmo tempo em que uma história é privilegiada, outras são negadas, em disputas, efetivamente de poder, que ocorrem no território (Raffestin, Barampama, 1998).

$\mathrm{Na}$ proposta de evidenciar emergências, faz-se necessário resistir ao paradigma do tempo sincrônico, que impõe a modernização sobre o território, promovendo a autonomia do mesmo por meio do reconhecimento das multitemporalidades. Nos territórios tradicionais se expressam diversas temporalidades, como da ancestralidade, da relação com a natureza e da ocupação histórica.

É importante superar as hierarquias, que são estabelecidas a partir da temporalidade dominante do global, para reduzir a influência do poder do global sobre o local. Logo, o 
reconhecimento das temporalidades faz com que as práticas sociais deixem de ser consideradas como resíduos, ganhando forma para o desenvolvimento autônomo (Sousa Santos, 2002) do território.

Há uma temporalidade estimável, mas incomensurável do ponto de vista da constituição dos modos de viver no território. Tal temporalidade se manifesta no presente como o tradicional, contudo está sempre em movimento, expondo saberes e práticas nos processos em curso, mas que foram constituídos a partir de gerações, transmitidos principalmente por meio da oralidade. A ancestralidade é apresentada como resquícios do passado, quando é situada em um ponto pretérito da reta linear da história. Contudo, a ancestralidade nos saberes e fazeres retoma o passado, ressignifica o presente onde se expõe, sempre considerando as possibilidades de futuro do território tradicional. O desprestígio atribuído ao conhecimento tradicional é sintoma da incapacidade das teorias e métodos científicos de compreendé-lo em sua complexidade. No entanto, cabe a observação atenta aos processos que estão em curso no presente, em que o tempo da ancestralidade constitui argumentação política das comunidades tradicionais quando reivindicam o direito de permanecer no território.

Esse contexto é evidente naquelas comunidades pesqueiras que são quilombolas. No Brasil, a Constituição Federal de 1988, reconhece o direito à terra ou território quilombola, associado à ancestralidade quilombola. Pelo menos em parte, isso tem garantido aos pescadores a manutenção de seus modos de viver, no local, muitas vezes a partir de relação econômicas, sociais e ambientais dispares ao que está estabelecido no global. No nordeste e norte brasileiro a luta pelo território associado à ancestralidade quilombola tem sido mais evidente. Contudo, cabe destacar outras ancestralidades que existem nos territórios, mas não são garantidas em leis, como aquelas culturas estabelecidas a partir do encontro. Chama-se de encontro a coexistência de matrizes culturais diversas que se ressignificam no local, que no caso das comunidades pesqueiras pode-se verificar no território nacional de forma diversa, o encontro do pescador indígena, com o pescador descente de africano escravizado, com o pescador lusitano sobretudo açoriano, com o pescador imigrante de outra região. No sul esse encontro configura um modo de viver chamado por alguns de açorianos, no litoral do sul e do sudeste de caiçaras, no Norte os ribeirinhos da Amazônia, no Nordeste os jangadeiros, as marisqueiras entre muitos outros.

Outra temporalidade que é negada diz respeito à congruência entre tempo da natureza e tempo da comunidade. Isso contrasta com o paradigma da modernização, cujo tempo de uso da natureza está cada vez mais subordinado ao da sociedade, e desqualifica os sujeitos e territórios cujas temporalidades estão associadas à dinâmica da natureza. A modernização impõe ao território, os ritmos do tempo da máquina, desconfigurando a natureza amplamente (Suertegaray, 2017).

Por outro lado, verifica-se que as práticas sociais vinculadas aos tempos da natureza, quando reconhecidas na dinâmica do território proporcionam a gestão dos recursos sem comprometer a sustentabilidade. As temporalidades da natureza, no local, além do manejo dos ecossistemas, têm grande influência sobre os modos de viver. Essas sociedades "de tempo lento" (M. Santos, 2006) exprimem um contraponto à sociedade global.

Retoma-se o exemplo dos ribeirinhos da Amazônia brasileira, cujos modos de viver e extrair os recursos do ambiente estão vinculados ao tempo da natureza, expresso nos períodos de cheia e seca dos rios. $O$ período da cheia define o trabalho em terra firme, a pesca de 
malhadeira nos rios. O período de seca é propício ao extrativismo nas várzeas, à pesca nos lagos. Respeitando os ritmos da natureza, expresso na dinâmica do rio e na maturação dos peixes, na seca ocorre a pesca de espécies como o pirarucu, aproveitando que esses peixes ficam contidos nos lagos, contudo essa situação de vulnerabilidade da espécie incide na promoção de regras de manejo, para que a exploração não extrapole os limites de recuperação dos estoques. Na Reserva de Desenvolvimento Sustentável Mamirauá, por exemplo, os comunitários desenvolveram uma metodologia de contagem dos peixes nos lagos, para estabelecer limites às pescarias.

Também se deve destacar a temporalidade que diz respeito ao tempo histórico de apropriação do território, o qual constitui um dos principais argumentos que garantem a presença das comunidades nos territórios tradicionais. Entretanto é comum que este seja desconsiderado nos contextos em que a modernização ou outros projetos do Estado avançam sobre os territórios tradicionais. Nesse sentido, a ocupação histórica do território, no presente é tratada como um vínculo indesejado com o passado e uma barreira para avanços futuros. Sousa Santos (2007) alerta para a necessidade de compreender a moldura temporal para além da duração da ação do Estado, para evidenciar experiências subalternas do Sul, respostas às necessidades imediatas de sobrevivência e de longa duração frente ao capitalismo e colonialismo.

No Brasil em diversos casos a permanência dos pescadores artesanais em seus territórios tradicionais tem sido subsidiada por argumentos relativos ao tempo de ocupação do território. É importante destacar os Termos de Autorização de Uso Sustentável - TAUS - (Brasil, 2010) que tem permitido a presença de pescadores artesanais em seus territórios, considerando a ocupação histórica. Várias comunidades já tem esse direito garantido, dentro e fora de unidades de conservação.

\section{Do paradigma da inferioridade de grupos e territórios à autonomia na diferença}

No âmbito das geografias das ausências, a naturalização das diferenças, sustenta a noção de inferioridade dos grupos sociais e seus territórios, o que está por trás do racismo ambiental. O paradigma da inferioridade de grupos consiste então na produção hierarquias e se expressam no território.

Para promover emergências na ciência geográfica, cabe destacar o processo de retomada da autonomia no território tradicional, por meio do reconhecimento das diferenças. Tem-se que superar a colonialidade do poder que converteu a diferença em desigualdade, articulando princípios da igualdade e da diferença. Para Sousa Santos (2002) quando desaparecem as hierarquias, permanecem as diferenças que a hierarquia necessita para se manter.

Diante disso, devem ser enfrentadas as desqualificações dos sujeitos, práticas, saberes e territórios. Deriva da hierarquia das classes e grupos sociais a constituição da hierarquia do acesso ao território, onde o argumento econômico é um dos principais fatores, o qual é bem aceito no campo político. A proposta de modernização dos territórios das comunidades tradicionais, amplamente produzidas em campanhas publicitárias, acaba por agradar seguimentos da sociedade que aspiram o acesso a tais recursos acrescidos de infraestruturas modernas.

No enfrentamento das inferiorizações propõe-se que a hierarquização de sujeitos e territórios seja convertida em reconhecimentos dos mesmos. Em contraponto a homogeneidade imposta pelo global, deve-se valorizar a heterogeneidade dos territórios, cujas diferenças se expressam nos saberes e fazeres, modos de viver, cultura. 
Os processos de construção, desconstrução e reconstrução, funcionalização, desfuncionalização e refuncionalização dos territórios são seletivos, logo não ocorrem nos territórios dominados por sujeitos sociais detentores do poder econômico e político. Pelo contrário ocorrem sobre territórios apropriados por grupos sociais considerados vulneráveis socialmente. Desta forma conclui-se que a instalação de empreendimentos não leva em conta somente o aspecto locacional, mas a população que será afetada, cuja falta de acesso a direitos básicos podem viabilizar remoções arbitrárias, pagamentos de indenizações irrisórias, e pouca reclamação (judiciária) frente a possíveis impactos. Compreende-se que determinados territórios são preferidos para a instalação de empreendimentos da modernização que são potencialmente causadores de danos ambientais e sociais.

Por outro lado, o paradigma de uso do território pelas comunidades tradicionais permitiu a manutenção das condições ambientais relativamente em equilíbrio. Entretanto, como as paisagens de beleza natural na atualidade são cada vez mais raras, a modernização propõe a refuncionalização do território, com instalação de infraestruturas que interessam às elites econômicas e políticas. Já os comunitários são paulatinamente desterritorializados, por não terem acesso a tais infraestruturas e serviços, e terem suas atividades normatizadas a partir de lógicas que são externas ao território tradicional.

Para a promoção dos territórios da diferença, que se apresenta como território de direitos específicos, torna-se fundamental a manutenção dos modos de viver, que se reinventam no processo de luta por territórios. Isso pressupõe que seja garantida ampla participação, desde o reconhecimento, que deve ser baseado na autoidentificação das comunidades tradicionais, até os usos que devem estar pautados na gestão comunitária do território.

A autonomia do território tradicional é recuperada quando externamente o território deixa de ser visto como inferior, passando a ser compreendido como prioritário no que tange a determinadas políticas. Internamente as diferenças hierárquicas são suprimidas, por meio de processos participativos e democráticos de gestão, que viabilizam a promoção dos modos de viver tradicionais.

O Movimento dos Pescadores e Pescadoras Artesanais, assim como o Conselho Pastoral dos Pescadores tem utilizado em suas reivindicações o termo racismo ambiental para destacar esse processo de inferiorização dos territórios das comunidades tradicionais. Enfatizam que a decisão de alocação de grandes empreendimentos causadores de impactos ambientais seleciona os territórios em que se encontram as populações negras e pobres. Por outro lado, a luta das comunidades tradicionais para permanecerem nos territórios ganhou fôlego a partir do momento em que o Brasil torna-se signatário da Convenção 169 da Organização Internacional do Trabalho (OIT, 2011), que reconhece direitos de povos indígenas e tribais. Esses compromissos atualmente fazem parte de normativas e decretos, como o Decreto 6040 (Brasil, 2007) que instituiu a Política Nacional de Desenvolvimento Sustentável dos Povos e Comunidades Tradicionais. Desta forma, a diferença destas comunidades em relação à sociedade capitalista geral foi convertida em reconhecimento, que resulta em direitos específicos, inclusive de uso do território.

\section{Do paradigma da superioridade do global à autonomia na escala local}

Destaca-se que na Geografia o destaque dado à global de forma preponderante ou até determinante às demais escalas também resulta na produção de ausências. Não se trata 
de descartar a importância de compreender o global, mas se faz necessário ter consciência que esta é a escala da modernização, e que por isso parece definir a relevância das demais escalas. Logo, mesmo quando se estuda o local, cabe questionar se tal estudo não corresponde aos objetivos do global, como ocorre em muitas pesquisas de prospecção de recursos naturais. Por outro lado, o local é desqualificado pelo global, por que não corresponde a sua proposta, estando geralmente relacionado a sujeitos que não aderem à proposta de modernização, como ocorre com os povos e comunidades tradicionais. Para evitar a produção de ausências se faz necessário evitar o universalismo, ou seja, a predominância de escalas independentemente de contextos específicos (Sousa Santos, 2011).

Para as geografias das emergências, o caminho apresentado é o de retomar a autonomia dos territórios tradicionais, afrontando o paradigma da superioridade do global, por meio da valorização da escala local. Para isso Sousa Santos $(2002,2007)$ entende que deve ser identificado no local o que não foi integrado na globalização hegemônica, bem como proporcionar a (des)globalização do local, de forma que sejam reconhecidos os efeitos internos e externos da globalização no território, por meio do resgate de saberes e práticas que não estão vinculadas ao global. Desta forma as pesquisas apontam para a importância da gestão do território a partir da dinâmica do local, reconhecendo as práticas de governança.

No projeto de modernização do território a dinâmica territorial está cada vez mais sujeitada à escala global, a partir de redes de tomadas de decisões alheias ao local. As comunidades se veem sujeitas às dinâmicas, processos e tecnologias, que não correspondem à realidade ambiental e social presente nos territórios tradicionais. Por outro lado, a decisão locacional de instalar essas atividades promotoras da modernização sobre territórios tradicionais se devem ao interesse dos países centrais de transferirem seus impactos e conflitos para países periféricos.

Para recuperar a autonomia frente aos efeitos externos da globalização, é necessário o reconhecimento e salvaguarda do território tradicional, para inibir o avanço das atividades da modernização, por meio de políticas públicas, garantindo a sustentabilidade do território tradicional. Desta forma, o território tradicional corresponde a uma alternativa à globalização, que pode expor questionamentos e possibilidades para a sociedade geral, quanto aos efeitos nocivos da mesma.

Também se deve destacar que o Estado viabiliza e promove a lógica global sobre o local, aderindo ao projeto de modernização do território e oferecendo os meios necessários para a instalação dos sintagmas da modernização, que estabelecem o novo território, mesmo reconhecendo o custo ambiental e social desse avanço. Nesse processo que se apresenta como um regresso colonizador (Sousa Santos, 2007), as comunidades são desassistidas pelo Estado, o qual não reconhece o uso tradicional do território. Neste contexto, é fundamental enaltecer a necessidade de conversão do papel do Estado como mediador entre global e local. Nesse sentido, o Estado deve reconhecer as multiterritorialidades no âmbito do território nacional, bem como suas singularidades e alternativas viáveis para o bem-estar social. Isto, fomentado por políticas públicas tende a promover, no presente, a ressurgência de grupos sociais que estavam em situação de invisibilidade. Assim, o Estado pode priorizar o local no território nacional, como a outra globalização que trata Milton Santos (2006).

A modernização do território apresenta ideários e padrões de vida (lê-se de consumo) estabelecidos no global, que poderiam ser alcançados no local, com a adesão aos seus pro- 
jetos. Nesse contexto cabe enfatizar a construção e distorção da compreensão de miséria. Sujeitos, que não aderem aos padrões de consumo estabelecidos no global, e que têm certa soberania alimentar, produzindo seus alimentos, e promovendo trocas e comércios que garantem a sua subsistência, quando constituem empecilhos à modernização do território, são apresentados como miseráveis. Destaca-se que por outro lado sujeitos que aderem ao processo de modernização e por meio do assalariamento conseguem sobreviver, não são apresentados dessa forma, mesmo que os recursos que recebem não sejam suficientes para manter os padrões de consumo, e que para isso tenham de recorrer a empréstimos de instituições financeiras, ficando endividados.

O conceito de emprego/postos de trabalho também é distorcido no processo de avanço da modernização do território, questão fundamental para a adesão do Estado a tais projetos. O projeto de modernização é acompanhado por promessas, não por compromissos, sendo que uma das preponderantes é a de oferecimento de empregos diretos e indiretos. Grandes empreendimentos, após a fase de construção das estruturas, costumam abrir algumas centenas de postos de trabalho. No entanto, deve-se questionar os milhares de postos de trabalho que são extintos devido à desterritorialização das comunidades que desenvolviam atividades no território, ou pior, das comunidades que passam a ser afetadas pelos efeitos nocivos, e danos ambientais, desses projetos modernos.

Na pesca artesanal brasileira a influencia do global sobre o local é bastante expressiva, quando se observa o avanço de portos, indústrias petroquímicas, mineração, entre outras atividades sobre o território tradicional. Destaca-se que todos estes empreendimentos se instalam com apoio do Estado, apresentam promessas de desenvolvimento econômico do local, e caracterizam as comunidades como miseráveis. Contudo, as comunidades locais não recebem os benefícios desse desenvolvimento, pelo contrário, veem suas práticas tradicionais serem desterritorializadas, por remoções arbitrárias ou por danos ambientais que resultam na queda na qualidade e quantidade de pescado. Desta forma constitui-se um quadro de insegurança alimentar, e a modernização efetivamente é geradora de desempregos diretos e indiretos, que intencionalmente não são estimados quando as propostas são apresentadas. Em outras palavras, pergunta-se quantos desempregos diretos e miséria gerou o crime ambiental promovido pela empresa SAMARCO Vale-BHP em 2015 que estabeleceu a zona de exclusão da pesca no Rio Doce, seus efluentes, e na costa do Espírito Santo até a Bahia?

\section{Do paradigma do produtivismo à autonomia na produção artesanal}

O paradigma do produtivismo constitui elemento fundamental na produção de ausências na Geografia, pois baseado nos critérios de produtividade capitalista entende que o crescimento/desenvolvimento econômico constitui objetivo inquestionável, justificando a modernização do território. Nega-se que o território é multidimensional, integrando dimensões culturais, sociais, econômicas, políticas, ambientais e muitas outras (Raffestin, 1980).

Na promoção de emergência, deve-se destacar processos de recuperação da autonomia do território tradicional, promovendo formas tradicionais de produção. Destaca-se que a produção tradicional foi mantida no capitalismo global, contudo de forma desqualificada para a manutenção da relação de subalternidade. Logo, para a recuperação da autonomia do território tradicional se faz necessário pensar a produção a partir do local, valorizando as atividades 
tradicionais, bem como relações e sistemas de produção alternativos, e questionar os limites do desenvolvimento econômico evidenciando suas consequências na escala do local.

Os critérios capitalistas de produtividade dizem respeito tanto à natureza quanto ao trabalho humano (Sousa Santos, 2002). Para a natureza, o meio encontrado é a potencialização dos seus processos por meio do emprego de ciência e tecnologia. Quanto ao trabalho isso se expressa na submissão dos trabalhadores aos ritmos de produção das máquinas e às demandas do consumo, mantendo-os cativos pelo assalariamento e por direitos trabalhistas, que são cada vez mais reduzidos. Como resultado, observa-se o desprestígio às atividades, sujeitos, grupos e territórios associados ao setor primário, especialmente aqueles que estão mais vinculados aos tempos da natureza.

No caso das comunidades extrativistas constitui um equívoco considerar que não há produção, mas somente extração. No mínimo é excessivamente simplificadora essa compreensão, pois limita a produção à coleta ou captura, negando a complexa cadeia que integra as atividades extrativistas, seus múltiplos atores, bem como saberes e fazeres constituídos no âmbito comunitário ao longo de gerações. Sendo assim, para a autonomia do território é fundamental que sejam garantidas as diversas territorialidades que integram a produção tradicional.

A relação entre trabalho urbano e trabalho rural também tem implicações nesse contexto onde cada vez mais os trabalhadores rurais vão ser estimulados a intensificarem seus processos para atender as demandas da sociedade urbana, a qual está sujeita aos processos e padrões de produtividade da modernização, logo irão demandar maior produção do trabalho rural. Os trabalhadores rurais que não se submetem a esses contextos, assim como seus territórios, serão considerados improdutivos.

O Estado irá incentivar o aumento da produção, muitas vezes induzindo para o rompimento com a lógica tradicional. Em outros contextos o Estado vai fomentar a substituição da atividade tradicional por outras atividades econômicas que promovam a modernização do território, cujos padrões de produtividade são apontados como superiores, o que resulta na constituição de um território completamente adverso ao tradicional, e as múltiplas dimensões se resumem à econômica.

Ao contrário, entende-se como fundamental a valorização e reconhecimento da pluriatividade das comunidades tradicionais, para garantir que os processos produtivos estejam de acordo com os ritmos e ciclos da natureza. Nesse contexto, o direito ao território constitui elemento indispensável na produção tradicional. Dialeticamente o mesmo território só se mantém, especialmente em condições ambientais estáveis, se a produção se manter em tais condições. Logo, a sustentabilidade da natureza deve constituir argumento para garantir e salvaguarda de tais territórios tradicionais, configurando estratégia local para o enfrentamento da crise ambiental concebida no global e que se expressa no território.

No Brasil a produção tradicional (da agricultura camponesa, pesca e extrativismo vegetal) tem papel fundamental na oferta de alimentos para a sociedade geral, contudo a autonomia das comunidades não deve ser reduzida para atender expectativas de consumo dos centros urbanos ligados à lógica global, que supõem que devem ter acesso a qualquer produto em qualquer lugar ou tempo. Essa lógica deve ser questionada com a valorização das condições da natureza, que oferece variedades de gêneros alimentares segundo sazonalidades. Logo, deve-se estimular a produção e consumo segundo as safras, bem como conscientizando quanto ao desperdício e necessidade de racionamento de determinados produtos em 
períodos. Tal postura é amplamente vivenciada nos territórios tradicionais, cujo consumo expressa seus modos de viver, e tende a contribuir para o questionamento à lógica global, cujo único compromisso é com a acumulação do capital.

Os padrões de produção do setor pesqueiro no Brasil, que prioriza a produção para a exportação, frequentemente vai desprestigiar a pesca artesanal frente a outras atividades como a pesca industrial e a aquicultura. No entanto, os incentivos de industrialização do setor pesqueiro oferecidos nos anos 1970 foram responsáveis pela drástica redução dos estoques (Pasquotto, 2007). Na atualidade as políticas de fomento à aquicultura industrial também têm disputado território com os pescadores artesanais (Silva, 2017). Por outro lado, os movimentos sociais da pesca como MPP e CPP apontam que cerca de $70 \%$ do pescado consumido no país é proveniente da pesca artesanal.

Uma distinção fundamental a ser apontada é que os pescadores artesanais são extrativistas. Ressalta-se isso porque na primeira década dos anos 2000 o Governo Federal Brasileiro incentivou e fomentou a criação de cooperativas de pescadores artesanais, a fim de fomentar e organizar a produção. Infelizmente, poucos desses empreendimentos tiveram êxito, pois a lógica de produção do extrativista não é simplesmente adequada aos modelos de empreendedorismo. Ainda há muito a ser decifrado sobre os limites e possibilidades da rede de comercialização do pescado da pesca artesanal, há de se considerar o papel dos atravessadores nesse processo, diferenciando os que exploram o trabalho do pescador artesanal, e os que viabilizam a comercialização e pertencem à própria comunidade. Além disso, os modelos fechados devem ser rechaçados, valorizando as estratégias das diferentes regiões e territórios, com a venda de beira de praia, as feiras e mercados populares do peixe, entre outras.

\section{Conclusões}

As reflexões aqui apresentadas de forma alguma devem ser compreendidas como diretrizes sobre o que fazer e o que não fazer na ciência. Pelo contrário, servem para vislumbrar que as decisões tomadas pelos pesquisadores e extensionistas estão dentro de um contexto maior de modernização do território, logo não são neutras e descompromissadas. Nesse sentido, podem conduzir para processos autoavaliativos e reflexivos na promoção de programas e projetos.

$\mathrm{Na}$ Geografia brasileira, as ausências promovidas nas pesquisas, e reafirmadas na falta de propostas de extensão, têm repercussão no território, e nas propostas de entendimento e ordenamento do mesmo, servindo de base para o avanço da modernização. Contudo, como foi apresentado têm sido promovidos projetos e programas de extensão, que têm priorizado as comunidades tradicionais de pescadores, em uma dialógica que tensiona o conhecimento científico. Muitos desses projetos têm permitido o acesso de pescadores às políticas públicas de que têm direito, bem como valorizado a sua participação em conselhos participativos.

O caminho apresentado para a superação de ausências e promoção de emergências na Geografia, seria de valorizar o presente e as experiência em curso no local. Desta forma enfrentando as propostas de futuro apresentadas pela modernização, e os ditames do global no território. As ausências operam por meio dos paradigmas da modernização, as emergências no destaque aos processos de recuperação de autonomia do território. Entende-se também que há um movimento concomitante de enfrentar as ausências e promover 
as emergências. É fundamental que se tenha atenção a esses contextos quando se concebe ou executa ações de pesquisa, ensino, e sobretudo de extensão, para que o efeito causado não reforce invisibilidades sociais.

O primeiro movimento seria então de enfrentar o paradigma do saber único para promover a autonomia do território reconhecendo os diversos saberes. Especialmente, destaca-se a importância dos processos dialógicos entre comunitários e deles com a sociedade geral, inclusive com o conhecimento científico, por meio dos diálogos de saberes. Na pesca os diálogos de saberes têm sido promovidos em espaços de gestão compartilhada, como os Fóruns de Pesca, e tem resultado em promoção de políticas públicas adequadas para a região e na reversão de atos normativos que impedem ou limitam a atividade tradicional no território em contextos de áreas protegidas.

O segundo movimento apresentado consiste em combater o paradigma do tempo sincrônico (linear) para a recuperação da autonomia do território por meio da valorização das múltiplas temporalidades. Trata-se do reconhecimento de temporalidades e de outras versões da história. Na pesca artesanal brasileira, quanto à ancestralidade, destacou-se o direito ao território conquistado pelas comunidades de pescadores quilombolas. Em relação à consonância entre tempo da sociedade e da natureza foi enfatizada a importância dos rios na definição dos modos de vida dos pescadores amazônidas. Sobre o tempo histórico, foram enaltecidas as múltiplas histórias de uso e ocupação do território, que passam a ser reconhecidas em políticas, como os Termos de Autorização de Uso Sustentável.

O terceiro movimento que foi exposto trata de arguir o paradigma de inferiorização de grupos e territórios para recuperar a autonomia do território por meio dos reconhecimentos. De um lado tem-se o contexto de desprestígio do território tradicional supondo a substituição do uso por atividades vinculadas à modernização e de outro a luta pelo reconhecimento dos povos tradicionais pelo direto de permanecer nos seus territórios. O Movimento dos Pescadores e Pescadoras Artesanais - MPP e o Conselho Pastoral dos Pescadores - CPP têm utilizado o termo "racismo ambiental" para destacar esses contextos onde a alocação de empreendimentos com grande potencial de degradação ambiental são instalados prioritariamente sobre territórios de populações negras, povos tradicionais e pobres. No caso dos pescadores, esse avanço é marcado pela resistência desses sujeitos à violência exercida pelos promotores da modernização, com apoio do Estado.

O quarto movimento evidenciado consiste em enfrentar o paradigma da superioridade do global para a promoção da autonomia do território, por meio da valorização da escala local. O paradigma do global valoriza as atividades relacionadas a essa escala, e define a partir dela a relevância das demais escalas. Desta forma é dada maior relevância à instalação de portos, indústrias petroquímicas, mineração e outras atividades que aderem ao projeto de modernização do território, estabelecido no global, do que às atividades que não aderem a esse plano. Para a desqualificação de tais atividades são estabelecidos conceitos a partir do global, como a ideia de miséria e de empregos diretos. No caso das comunidades de pescadores ao mesmo tempo que frequentemente são apresentadas como miseráveis, observa-se que justamente o avanço da modernização resulta na sujeição destes a um contexto de insegurança alimentar. Quando a modernização defende empregos diretos e indiretos, não contabiliza os desempregos diretos e indiretos que promove quando desterritorializa tais comunidades. 
O quinto, e último, movimento apresentado seria de questionar o paradigma do produtivismo estabelecido no global, para recuperar a autonomia do território valorizando a produção local baseada em métodos artesanais. Deve-se questionar os padrões de consumo que desejam definir os processos produtivos, apropriando-se do trabalho e não respeitando os ritmos da natureza. No caso do setor pesqueiro brasileiro, destaca-se que o próprio Estado fomentou a partir da década de 1970 a industrialização, chegando ao ponto de que nos anos 1990 foi observável o colapso de diversos estoques. Na atualidade a prioridade tem sido dada à aquicultura industrial, que tem avançado sobre territórios de pesca tradicionais. Outra questão sobre a produção a ser destacada são os limites da análise da cadeia produtiva da pesca artesanal, que por vezes vai entender o pescador como empreendedor, rompendo com a lógica extrativista.

Por fim destaca-se a necessidade da reflexão crítica dos pesquisadores e extensionista, sobre o quanto seus projetos reafirmam invisibilidades sociais. No que tange a extensão universitária, acredita-se que tal reflexão deve qualificar as ações, e contribuir na construção de agendas que de fato promovam emergências de sujeitos e territórios. Acrescenta-se o potencial desses contextos na formação de recursos humanos críticos, e comprometidos com o enfrentamento de invisibilidades sociais e subalternidade de determinados grupos e seus territórios.

\section{Referências bibliográficas}

Arzeno, M. (2018). Extensión en el territorio y territorio en la extensión. Aportes a la discusión desde el campo de la Geografía. +E: Revista de Extensión Universitaria, (8), 3-11.

Castro-Gómez, S. (2005). Ciências sociais, violência epistêmica e o problema da "invenção do outro. In Lander, E. (Org.). A colonialidade do saber: eurocentrismo e ciências sociais Perspectivas latino-americanas. Títulos del Programa Sur-Sur (pp. 80-88). CLACSO.

De Paula, C.Q. (2013). Gestão Compartilhada dos Territórios da Pesca Artesanal: Fórum Delta do Jacuí (Dissertação de Mestrado). Universidade Federal do Rio Grande do Sul.

- (2015). Análise Dialógica de Conteúdo e Diálogos de Saberes. Boletim Gaúcho de Geografia, (42), 44-63.

(2018). Geografia(s) da Pesca Artesanal Brasileira (Tese de Doutorado). Universidade Federal do Rio Grande do Sul.

De Paula, C.Q.; Suertegaray, D.M.A. (2018). Modernização e Pesca Artesanal Brasileira: a expressão do "mal limpo". Terra Livre: a Geografia toma partido, (50), 97-130.

Leff, E. (2004). Racionalidad ambiental - la reapropriación social de la naturaleza. Economía, Sociedad y Territorio, (31), 863-879.

Morin, E. (1990). Introdução ao Pensamento Complexo. Lisboa: Instituto Piaget.

(1996). Ciência com consciência. Bertrand Brasil: Rio de Janeiro.

(2005). O Método 6: ética. Sulina: Porto Alegre.

Pasquotto, V.F. (2007). Comercialização, políticas públicas e reprodução social na pesca artesanal. In Lobo, A.C. (Org.). Nas redes da pesca artesanal (pp. 225-239). IBAMA: Brasília,

Porto-Gonçalves, C.W. (2010). De saberes e de territórios: diversidade e emancipação a partir da experiência Latino-Americano. GEOgraphia, (8), 37-52. 
Quijano, A. (2005). Colonialidade do poder, eurocentrismo e América Latina. In Lander (Org.). A colonialidade do saber: eurocentrismo e ciências sociais Perspectivas latino-americanas. Títulos del Programa Sur-Sur. CLACSO.

Raffestin, C. (1980). Pour une géographie du pouvoir. Paris: LITEC.

(1986). Ecogenèse territoriale et territorialité. In Auriac, F.; Brunet, R. Espaces, jeux et enjeux (pp. 175185). Paris: Fayard \& Fondation Diderot.

(2012). Space, territory, and territoriality. Environment and Planning D. In Society and Space, (30), 121-141.

Raffestin, C.; Barampama, A. (1998). Espace et pouvoir. In Bailly, A. Les concepts de la géographie humaine (pp. 63-71). Paris: Armand Colin.

Santos, M. (2006). A Natureza do Espaço: Técnica e Tempo, Razão e Emoção. São Paulo: EDUSP.

Silva, C.A. (2017). Modernização, Conflitos Territoriais e Sujeitos Sociais de Culturas Tradicionais: contribuições da Geografia na leitura da produção da totalidade do espaço brasileiro no século XXI. In Suertegaray, D.M.A.; Pires, C.L.Z.; Silva, C.A.; De Paula, C.Q. (Orgs.). Geografia e Conjuntura Brasileira (pp. 249-274). Rio de Janeiro; Consequência.

Silva, J.B., Dantas, E.W.C. (2005). A pós-graduação em Geografia no Brasil: uma contribuição à política de avaliação. Revista da ANPEGE, (2), s/n.

Sousa Santos, B. de (2002). Para uma sociologia das ausências e uma sociologia das emergências. Revista Crítica de Ciências Sociais, (63), 237-280.

— (2007). Para além do Pensamento Abissal: Das linhas globais a uma ecologia de saberes. Revista Novos Estudos Cebrap, (79), 71-94.

(2011). Epistemologías del Sur. Utopía y Praxis Latinoamericana, (54), 17-39.

Sousa Santos, B. de; Meneses, M.P.G.; Nunes, J.A. (2006). Conhecimento e Transformação Social: por uma ecologia de saberes. Hiléia - Revista de Direito Ambiental da Amazônia, (6), 11-104.

Spósito, E.S. (2016) A pós-graduação em Geografia no Brasil: Avaliação e tendências. In Spósito, E.S.; Silva, C.A.; Sant'anna Neto, J.L.; Melazzo, E.S. A diversidade da Geografia Brasileira. Escalas e Dimensões da Análise e da Ação (pp. 523-543). Rio de Janeiro: Consequência.

Suertegaray, D.M.A. (2017). Religar a Geografia: natureza e sociedade. Porto Alegre: Compasso Lugar-Cultura. Suertegaray, D.M.A.; De Paula, C.Q. (2019). Geografia e questão ambiental, da teoria à práxis. Ambientes: revista de Geografia e Ciência Política, (1), 79-102.

Tomáz. A.F. \& Santos, G. (Orgs.) (2016). Conflitos Socioambientais e Violações de Direitos Humanos em Comunidades Tradicionais Pesqueiras no Brasil. Brasília: Conselho Pastoral dos Pescadores.

\section{Relatórios e Leis}

Brasil (2007). Decreto No 6.040. Política Nacional de Desenvolvimento Sustentável dos Povos e Comunidades Tradicionais. Recuperado em 16 de janeiro de 2019, de http://www.planalto.gov.br/ccivil_03/_ato20072010/2007/decreto/d6040.htm

Brasil (2010). Portaria No 89. Termo de Autorização de Uso Sustentável - TAUS. Recuperado em 16 de janeiro de 2019, de www. planejamento.gov.br/assuntos/patrimonio-da.pdf/portaria-89-2010-tau.pdf

Coordenação de Aperfeiçoamento de Pessoal de Nível Superior (2005). Plano Nacional de Pós-Graduação PNPG 2005-2010. Recuperado em 10 de junho de 2019, de https://www.capes.gov.br/images/stories/download/editais/PNPG_2005_2010.pdf 
Coordenação de Aperfeiçoamento de Pessoal de Nível Superior (2010). Plano Nacional de Pós-Graduação - PNPG 2011-2020. Recuperado em 10 de junho de 2019, de https://www.capes.gov.br/images/stories/ download/PNPG_Miolo_V2.pdf

Coordenação de Aperfeiçoamento de Pessoal de Nível Superior (2016). Documento da Área da Geografia. Recuperado em 10 de junho de 2019, de https://capes.gov.br/images/documentos/Documentos_de_ area_2017/36_geog_docarea_2016.pdf

Organização Internacional do Trabalho (2011). Convenção n 169 sobre povos indígenas e tribais. Recuperado em 16 de janeiro de 2019, de http://portal.iphan.gov.br/uploads/ckfinder/arquivos/Convencao_169_OIT.pdf 